\title{
STUDI ERGONOMI KURSI KERJA PENUNJANG KEGIATAN WORK FROM HOME BAGI KARYAWATI HAMIL
}

\author{
Riaz Muhammad Grahara ${ }^{1}$, Sulistyo Setiawan ${ }^{2}$ \\ 1 Program Studi Desain Produk, Fakultas Arsitektur dan Desain, ITENAS Bandung \\ 2 Program Studi Desain Produk, Fakultas Arsitektur dan Desain, ITENAS Bandung \\ Email : riazmuhamad51@gmail.com¹, sulistyo@itenas.ac.id ${ }^{2}$
}

Page | 19

\begin{abstract}
ABSTRAK
Kursi Kerja merupakan salah satu fasilitas penunjang kegiatan kerja yang sangat berpengaruh untuk mengoptimalkan kerja penggunanya. Pengguna yang dimaksud adalah karyawati hamil yang bekerja di kantor namun karena pandemi Covid-19, maka pekerjaan tersebut dilakukan dari rumah (Work From Home/WFH). Di dalam kegiatan WFH tersebut sebagian besar dari mereka banyak menggunakan kursi dengan posisi duduk dalam waktu yang cukup lama. Dari observasi yang dilakukan penulis menemukan bahwa kursi yang dapat memfasilitasi karyawati hamil di lingkungan rumah tidak tersedia, sehingga hasil kerja yang dicapai tidak optimal karena mereka mengalami ketidaknyamanan pada bagian punggung bawah yang disebabkan oleh perubahan bentuk tubuh. Tujuan utama dari penelitian ini adalah menemukan ukuran kursi kerja yang ergonomis bagi karyawati hamil. Adapun metode yang digunakan pada penelitian ini adalah analisis ergonomi melalui pengukuran menggunakan metode antropometri dari Tilley \& Dreyfuss. Dari hasil penelitian dapat disimpulkan bahwa ukuran yang tepat untuk diaplikasikan pada kursi kerja wanita hamil yaitu tinggi popliteal 33 $\mathrm{cm}$, panjang popliteal $45 \mathrm{~cm}$, tinggi pantat-siku $18,5 \mathrm{~cm}$, jarak ujung jari-siku $38,5 \mathrm{~cm}$, tinggi lumbar $20,5 \mathrm{~cm}$, tinggi pantat-bahu $54 \mathrm{~cm}$, tinggi duduk normal $83 \mathrm{~cm}$, jarak lumbar-pusar $56 \mathrm{~cm}$, lebar pinggul $60 \mathrm{~cm}$, tinggi pinggul $25 \mathrm{~cm}$, dan lebar bahu $54 \mathrm{~cm}$.
\end{abstract}

Kata kunci : Kursi kerja, wanita hamil, ergonomi.

\begin{abstract}
The work chair is one of the facilities to support work activities which is very influential to optimize the work of its users. The user in question is a pregnant female employee who works in an office but due to the Covid-19 pandemic, the work is carried out from home (Work From Home / WFH). In the WFH activity, most of them used chairs and sat for a long time. From the observations made, the writer found that chairs that could facilitate pregnant female workers in the home environment were not available, so that the work achieved was not optimal because they experienced discomfort in the lower back caused by changes in body shape. The main objective of this study is to find an ergonomic work chair size for pregnant female employees. The method used in this research is ergonomic analysis through measurement using the anthropometric method from Tilley \& Dreyfuss. From the results of the study it can be concluded that the right size to be applied to a pregnant woman's work chair is popliteal height $33 \mathrm{~cm}$, popliteal length $45 \mathrm{~cm}$, butt-elbow height 18,5 cm, toe-to-elbow distance 38,5 $\mathrm{cm}$, lumbar height 20,5 cm, butt-shoulder height $54 \mathrm{~cm}$, normal sitting height $83 \mathrm{~cm}$, lumbar-navel distance $56 \mathrm{~cm}$, hip width $60 \mathrm{~cm}$, hip height $25 \mathrm{~cm}$, and shoulder width $54 \mathrm{~cm}$.
\end{abstract}

Keywords: Work chair, pregnant woman, ergonomics. 


\section{PENDAHULUAN}

Menurut BKKBN pada tahun 2020 di indonesia terjadi sekitar empat ratus ribu kehamilan yang tidak direncanakan. Kejadian tersebut akan berimbas pada kehamilan di tahun 2021 yang diperkirakan 4,8 juta kelahiran/kehamilan baru di Indonesia [1]. Sejalan dengan hasil persentase tingginya status wanita yang bekerja dibanding ibu rumah tangga di perkotaan pada tahun 2018 sekitar 46,12\%, bekerja sebagai buruh/karyawan/pegawai menempati posisi tertinggi yaitu untuk perempuan sebesar 50,88 \% [2]. Bersamaan dengan masa pandemi Covid-19, pemerintah menerbitkan kebijakan yang berkaitan dengan prioritas terhadap karyawan wanita hamil untuk melakukan Work From Home yang dituangkan melalui Surat Edaran Menteri Dalam Negeri Nomor 440/2431/SJ [3]. Dengan kondisi tersebut wanita hamil akan tetap melanjutkan aktivitas bekerja di rumah untuk pemenuhan kebutuhan dan kesejahteraan, selama aktivitas tersebut mendukung dan kondusif. Kurangnya bahkan tidak adanya ketersediaan fasilitas penunjang kerja di rumah seperti kursi kerja dan meja kerja khususnya bagi wanita hamil, dapat menurunkan kualitas dan kemapuanya dalam bekerja, dikarenakan ketidaknyamanan dan keluhan nyeri di punggung bawah (NPB) yang diakibatkan oleh perubahan bentuk dan dimensi pada tubuh yang berpengaruh secara signifikan. Berdasarkan hasil penelitian terhadap wanita hamil, terdapat 20 responden $(48,8 \%)$ wanita hamil beresiko sedang terjadinya trauma fisik dalam bekerja karena posisi tubuh membungkuk saat bekerja, dan ada 4 responden $(9,7 \%)$ beresiko tinggi terjadinya trauma fisik [4]. Survey yang dilakukan oleh University of Ulster pada tahun 2014, bahwa 70\% dari total 157 wanita hamil mengalami nyeri punggung bagian bawah [5].

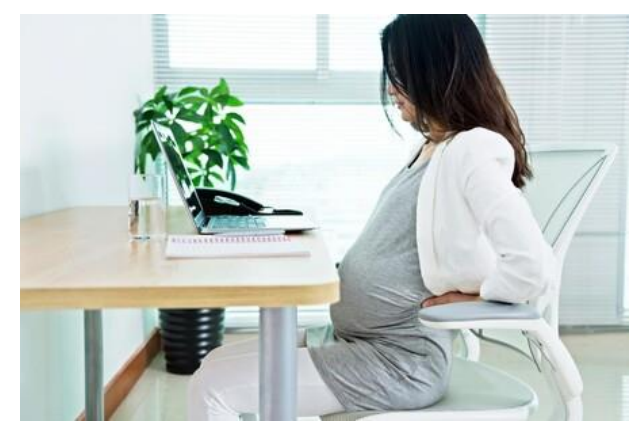

\section{Gambar 1. Nyeri Punggung Bawah Ketika Bekerja Duduk}

Sumber : 1 https://www.honestdocs.id/

Dari data survey kuesioner online yang dilakukan oleh penulis tentang ketersediaan kursi khusus wanita hamil, dari 27 responden sekitar 85,2 \% tidak memiliki kursi tersebut di area rumah. Penggunaan kursi masih dengan fasilitas kursi seadanya meskipun dalam kegiatan kerja dalam rangka Work From Home.

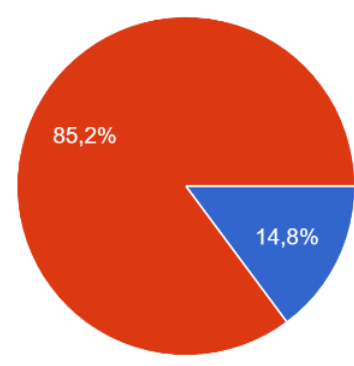

Page | 20 
Penggunaan kursi kerja yang masih berorientasi pada ergonomi tubuh normal/umum dan seadanya di area rumah, tentunya dapat memperburuk kenyamanan karena penggunaanya yang tidak sesuai dengan keadaan tubuh wanita hamil agar dapat bekerja secara optimal. Penggunaan alat kerja yang benar dapat mencegah bahaya kecelakaan dan mengurangi gangguan psikis [6]. Karena posisi duduk yang baik dapat berpengaruh sebesar $75 \%$ untuk perkembangan janin dan menurunkan resiko Abortus sebesar 15\% [7].

Berangkat dari hal tersebut maka dibutuhkan kursi kerja yang memiliki dimensi yang tepat berdasarkan faktor ergonomi yang sesuai dengan antropometri karyawati hamil dan kegitan kerjanya yang dilakukan di rumah.

\section{METODE PENELITIAN}

Penelitian ini menggunakan metode kuantitatif yang bertujuan menemukan ukuran rata rata pada tinggi popliteal, panjang popliteal, tinggi pantat-siku, tinggi duduk normal, lebar pinggul, lebar bahu, tinggi pantat, jarak ujung jari-siku, tinggi lumbar, jarak pusar-lumbar, dan tinggi pantat-bahu. Data dan informasi yang digunakan dalam penelitian ini adalah data primer melalui pengukuran seacara langsung oleh penulis terhadap 30 responden wanita hamil. Menurut Roebuck dalam Wardani [8] antropometri adalah ilmu yang berkaitan dengan pengukuran dimensi dan cara untuk mengaplikasikan karakteristik tertentu dari tubuh manusia [8]. Dari data yang telah didapat, akan dipilih dan dihitung untuk hasil dari persentil 95\% dan persentil 5\% menggunakan analisa ergonomi menggunakan metode pengukuran antropometri yang akan diaplikasikan pada perancangan desain kursi kerja wanita hamil agar dapat memberikan kenyaman untuk hasil kerja yang optimal.

\section{PEMBAHASAN}

\subsection{Ergonomi dan Kenyamanan}

Kata ergonomis berasal dari kata Yunani, ergon (kerja) dan nomos (hukum). Ergonomi adalah ilmu yang mempelajari interaksi antara manusia dengan elemen-elemen lain dalam suatu sistem, serta profesi yang mempraktikan teori, prinsip, data dan metode dalam perancangan untuk mengoptimalkan sistem agar sesuai dengan kebutuhan, kelemahan, dan keterampilan manusia. Menurut artikel yang dikutip rancangan yang ergonomis dapat meingkatkan efisiensi, efektifitas dan produktivitas kerja, serta dapat menciptakan sistem serta lingkungan [9]. Peningkatan efisiensi kerja sangat dipengaruhi oleh ergonomi ketika terjadinya interaksi antara manusia dan produk yang dipakai.

Kenyaman secara teoritis didefinisikan sebagai kondisi telah terpenuhinya kebutuhan dasar manusia dalam kesenangan, ketentraman, dan kebebasan (the state of having met basic human needs for ease, relief, and transcendence) [10], ketika meningkatnya atau terpenuhinya kenyamanan, maka produktivitas dan hasil kerja yang optimal juga akan meningkat. Produktivitas dan kinerja merupakan salah satu dari prinsip ergonomi. Kinerja pekerja terletak dalam aspek kerja termasuk egonomi itu sendiri. Untuk menghasilkan produktivitas dan kinerja, ergonomi akan merancang pekerjaan yang akan cocok untuk para pekerja sesuai dengan kebutuhan dasar para pekerja.

\subsection{Antropometri}

Istilah antropometri berasal dari "anthro" yang berarti manusia dan "metri" yang berarti ukuran. Anthropometri adalah pengetahuan yang menyangkut pengukuran tubuh manusia khususnya dimensi tubuh [11]. Ilmu antropometri sendiri merupakan bagian dari ilmu egonomi yang khusus dalam mempelajari ukuran tubuh. Pemanfaatan aspek antropometri pada perancangan akan berimplikasi positif pada kenyamanan pengguna [9] Adanya perbedaan dimensi dan ukuran tubuh yang mengalami perubahan pada wanita hamil yang berbeda dari wanita normal, maka dalam perancangan kursi kerja bagi wanita hamil, pengukuran antropometri sangat dibutuhkan untuk meningkatkan kenyaman melalui ukuran kursi yang sesuai dengan dimensi tubuh wanita hamil. Oleh karena itu pengukuran antropometri akan diambil dari hasil rata-rata, karena berdasarkan jurnal yang dikutip menyatakan tidak ada dua orang yang persis sama, termasuk kembar identik [12] 


\subsection{Data Antropometri}

Kegiatan pengukuran dilakukan penulis di klinik Posyandu Cempaka Kecamatan Kawalu Kota Tasikmalaya, yang bersamaan dengan penyeluhan dan pemeriksaan rutin terkait Covid-19 terhadap ibu hamil oleh Bidan Reni Hunariah, AM. Keb. pengukuran dilakukan selama tiga sesi.

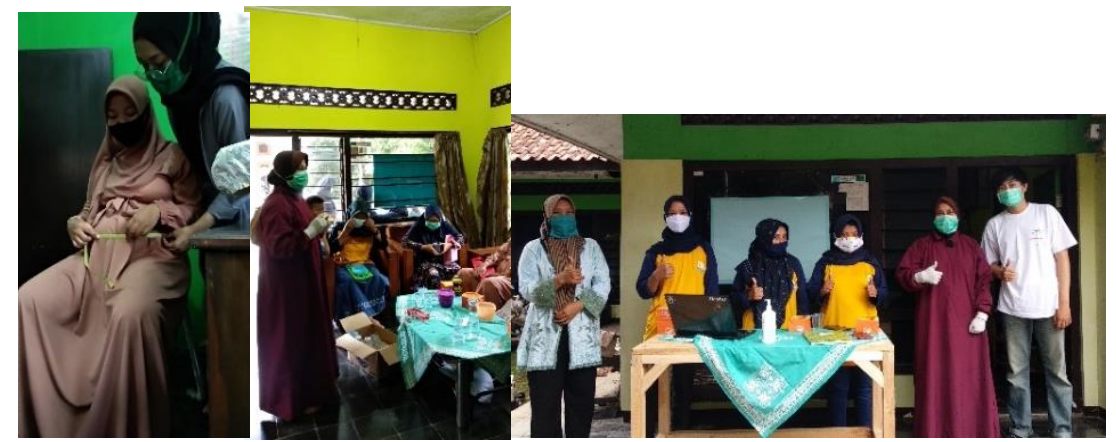

Gambar 2. Kegiatan Pengukuran (Sumber : Dokumentasi Pribadi)

Berdasarkan kebutuhan untuk pemenuhan standar ergonomi bagi kursi kerja wanita hamil melalui metode antropometri, penulis melakukan pengukuran langsung terhadap wanita hamil dengan 30 responden. Berikut data antropometri yang telah didapat :

Keterangan :

1. Tinggi Popliteal

2. Panjang Popliteal

3. Tinggi Pantat-Siku

4. Jarak Ujung Jari-Siku

5. Tinggi Lumbar

6. Tinggi Pantat-Bahu

7. Tinggi Duduk Normal

8. Jarak Lumbar-Pusar

9. Lebar Pinggul

10. Tinggi Pinggul

11. Lebar Bahu
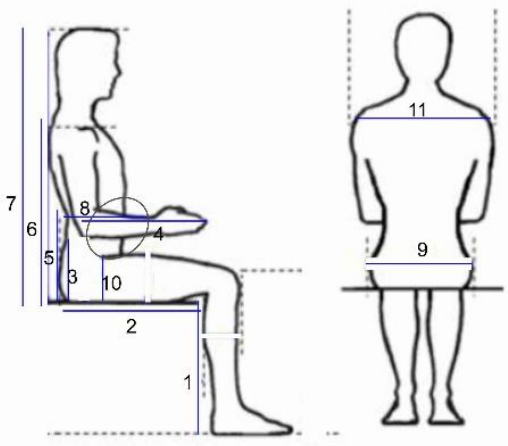

Tabel 1. Data Hasil Pengukuran (Sumber : Pribadi)

\begin{tabular}{|l|l|l|l|l|l|l|l|l|l|l|l|}
\hline \multicolumn{1}{|c|}{ Nama } & $\mathbf{1}$ & $\mathbf{2}$ & $\mathbf{3}$ & $\mathbf{4}$ & $\mathbf{5}$ & $\mathbf{6}$ & $\mathbf{7}$ & $\mathbf{8}$ & $\mathbf{9}$ & $\mathbf{1 0}$ & $\mathbf{1 1}$ \\
\hline Nurul & 34 & 39 & 27 & 38 & 23 & 50 & 76 & 28 & 44 & 16 & 41 \\
\hline lis & 38 & 44 & 28 & 41 & 24 & 51 & 76 & 26 & 51 & 18 & 44 \\
\hline Nunur & 34 & 40 & 22 & 37 & 25 & 46 & 75 & 29 & 43 & 16 & 44 \\
\hline Poppy & 39 & 48 & 20 & 41 & 25 & 47 & 75 & 24 & 45 & 12 & 45 \\
\hline Thursinah & 38 & 49 & 24 & 41 & 31 & 53 & 81 & 31 & 45 & 18 & 49 \\
\hline Elli & 35 & 42 & 24 & 36 & 22 & 50 & 75 & 31 & 51 & 16 & 42 \\
\hline Yanti & 40 & 50 & 29 & 43 & 30 & 52 & 82 & 33 & 53 & 24 & 47 \\
\hline Etip & 39 & 44 & 30 & 38 & 29 & 49 & 79 & 23 & 44 & 18 & 44 \\
\hline Riyana & 40 & 45 & 24 & 39 & 22 & 48 & 79 & 27 & 50 & 17 & 45 \\
\hline Ririn & 35 & 40 & 18 & 34 & 23 & 52 & 77 & 29 & 49 & 19 & 47 \\
\hline Yani & 39 & 46 & 24 & 40 & 30 & 49 & 79 & 32 & 59 & 17 & 46 \\
\hline
\end{tabular}




\begin{tabular}{|c|c|c|c|c|c|c|c|c|c|c|c|}
\hline Nama & 1 & 2 & 3 & 4 & 5 & 6 & 7 & 8 & 9 & 10 & 11 \\
\hline Sakinah & 40 & 47 & 25 & 39 & 30 & 50 & 84 & 29 & 52 & 20 & 50 \\
\hline Annisa & 38 & 48 & 25 & 39 & 30 & 49 & 75 & 33 & 57 & 23 & 54 \\
\hline Ai Rifa & 43 & 50 & 23 & 41 & 34 & 54 & 84 & 37 & 58 & 24 & 50 \\
\hline Yusi & 39 & 46 & 19 & 39 & 26 & 44 & 73 & 27 & 43 & 16 & 45 \\
\hline Raisa & 39 & 48 & 30 & 41 & 30 & 52 & 85 & 33 & 50 & 23 & 45 \\
\hline Wafda & 37 & 44 & 28 & 39 & 24 & 51 & 76 & 26 & 51 & 19 & 44 \\
\hline Deti & 33 & 39 & 18 & 33 & 22 & 51 & 75 & 27 & 50 & 19 & 46 \\
\hline Siti & 38 & 43 & 24 & 39 & 22 & 48 & 79 & 27 & 50 & 17 & 45 \\
\hline Emmi & 41 & 51 & 23 & 41 & 33 & 53 & 84 & 37 & 58 & 24 & 50 \\
\hline Lidya & 40 & 50 & 21 & 38 & 31 & 50 & 80 & 34 & 57 & 19 & 46 \\
\hline Tiara & 35 & 39 & 25 & 37 & 23 & 50 & 75 & 25 & 44 & 18 & 43 \\
\hline Latipah & 34 & 40 & 20 & 32 & 24 & 51 & 78 & 27 & 48 & 19 & 45 \\
\hline Desi & 48 & 53 & 23 & 40 & 35 & 53 & 84 & 37 & 58 & 25 & 51 \\
\hline Fitri & 45 & 51 & 23 & 39 & 34 & 52 & 82 & 36 & 57 & 23 & 50 \\
\hline Bella & 40 & 46 & 24 & 38 & 22 & 47 & 77 & 25 & 52 & 18 & 44 \\
\hline Dita & 38 & 46 & 25 & 37 & 30 & 49 & 73 & 33 & 59 & 25 & 54 \\
\hline Lani & 36 & 34 & 24 & 40 & 25 & 53 & 73 & 26 & 44 & 18 & 42 \\
\hline Yuni & 37 & 40 & 23 & 39 & 30 & 50 & 75 & 31 & 59 & 20 & 57 \\
\hline Dela & 36 & 39 & 18 & 33 & 23 & 52 & 76 & 29 & 49 & 17 & 47 \\
\hline Mean & 38,2 & 44,7 & 23,7 & 38,4 & 27,1 & 50,2 & 73,8 & 29,7 & 49,4 & 19,2 & 46,7 \\
\hline SD & 3,62 & 4,61 & 3,27 & 2,57 & 4,18 & 2,28 & 5,63 & 3,97 & 5,94 & 3,17 & 4,13 \\
\hline
\end{tabular}

Dalam menemukan ukuran yang tepat, maka metode antropometri yang dipakai menggunakan rumus untuk hasil dari persentil 95 dan 5 pada tiap bagian dimensi tubuh yang dibutuhkan. Formula yang dipakai adalah dari Tilley \& Dreyfuss [12].

$S D=\sqrt{ }\left(\frac{(x i-x)^{2}}{30}\right)$

Persentil 95=Mean+(1,65 $\times$ SD)

Persentil 5=Mean-(1,65 x SD)

Persentil 50=Mean

Mean = Jumlah Data masing masing dibagi jumlah responden

$\mathrm{SD}=$ Standar deviasi untuk mengestimasi persentil

\section{Tinggi Popliteal} Standar Deviasi $/ S D=\sqrt{ }\left(\frac{(x i-x)^{2}}{30}\right)$
$=3,62$

$$
\begin{array}{r}
P 95 \%=38,2+(1,65 \times 3,62) \\
=38,2+5,97 \\
=44,17 \mathrm{~cm}
\end{array}
$$$$
\text { P 5\% = 38, } 2-(1,65 \times 3,62)
$$$$
=38,2-5,97
$$$$
=32,23 \mathrm{~cm}
$$

Tinggi Popliteal/tinggi dari kaki kursi menggunakan persenti $5^{\text {th }}$ yaitu $32,23 \mathrm{~cm}=33 \mathrm{~cm}$. penggunaan persentil $5^{\text {th }}$ dimaksudkan agar wanita hamil yang memiliki postur pendek dapat menggunakanya sehingga posisi kaki tidak menggantung dan menimbulkan tekanan. Sementara untuk wanita hamil dengan postur tinggi dapat menggunakanya juga, yaitu mengkombinasikanya dengan panjang popliteal [14]. Pada umumnya ditambah allowance $5 \mathrm{~cm}$ untuk penggunanan alas kaki atau sepatu [13]. Tetapi kursi ini diperuntukan untuk penggunaan di area dalam rumah yang tidak memakai alas kaki/sepatu. 


\section{Panjang Popliteal}

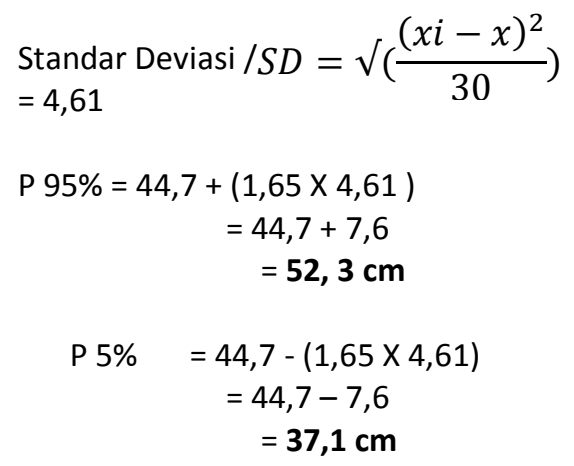

\section{Tinggi Pantat-Siku}

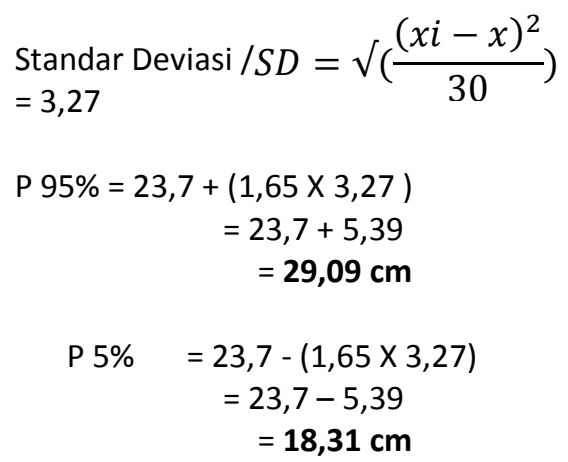

Jarak Ujung Jari - Siku

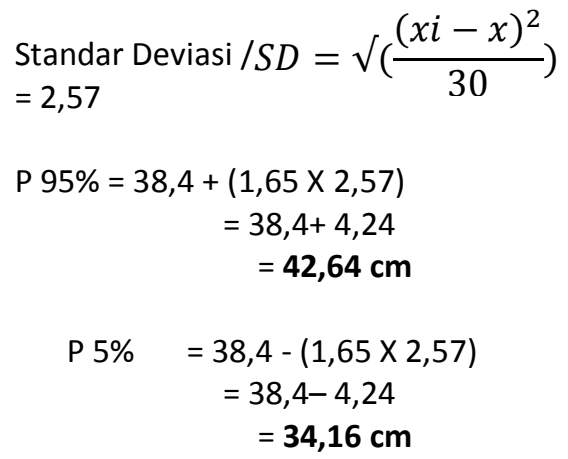

\section{Tinggi Lumbar}

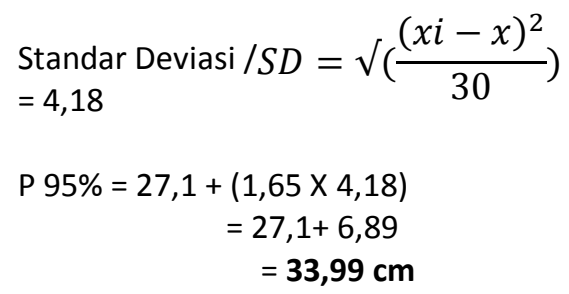

Panjang Popliteal/panjang dari ujung pantat hingga lipatan lutut menggunakan persentil $50^{\text {th }}$ yaitu $44,7 \mathrm{~cm}=45 \mathrm{~cm}$. penggunann persentil $50^{\text {th }}$ merupakan ukuran rata-rata yang tepat dapat digunakan seluruh populasi. Batas minimal pada ukuran ini tidak mudah ditentukan, maka penggunaan ukuran $50^{\text {th }}$ ini sangat tepat [14]. Jika terlalu panjang akan menekan bagian bawah lutut, jika terlalu pendek akan menekan bagian tengah paha.

Tinggi pantat-siku/tinggi sanggahan tangan menggunakan persentil $5^{\text {th }}$ yaitu $18,31 \mathrm{~cm}=\mathbf{1 8 , 5} \mathrm{cm}$. penggunann persentil $5^{\text {th }}$ dimaksudkan agar wanita hamil yang memiliki postur tinggi dapat menggunakan posisi siku yang rendah, juga wanita hamil yang borpostur pendek dapat juga menggunakan posisi siku yang rendah.

Jarak ujung jari-siku/panjang sanggahan tangan menggunakan persentil $50^{\text {th }}$ yaitu $38,4 \mathrm{~cm}=38,5 \mathrm{~cm}$ peggunaan persentil $50^{\text {th }}$ dimaksudkan agar wanita hamil yang berlengan pendek dan berlengan panjang dapat dengan nyaman menggunakan ukuran ini. 


\section{Tinggi Pantat - Bahu}

Standar Deviasi $/ S D=\sqrt{ }\left(\frac{(x i-x)^{2}}{30}\right)$
$=2,28$

$P 95 \%=50,2+(1,65 \times 2,28)$

$=50,2+3,76$

$=53,96 \mathrm{~cm}$

P $5 \%=50,2-(1,65 \times 2,28)$

$=50,2-6,89$

$=43,31 \mathrm{~cm}$

\section{Tinggi Duduk Normal}

Standar Deviasi $/ S D=\sqrt{ }\left(\frac{(x i-x)^{2}}{30}\right)$
$=5,63$

Tinggi duduk normal/ sandaran-kepala menggunakan persentil $95^{\text {th }}$ yaitu $83,08 \mathrm{~cm}=83 \mathrm{~cm}$. penggunaan persentil tersebut dimaksudkan agar wanita hamil yang memiliki postur pendek dapat menggunakan sandaran kepala tersebut, juga

$P 95 \%=73,8+(1,65 \times 5,63)$

$=73,8+9,28$

$=83,08 \mathrm{~cm}$

P $5 \%=73,8-(1,65 \times 5,63)$

$=73,8-9,28$

$=64,51 \mathrm{~cm}$

\section{Jarak Lumbar - Pusar} Standar Deviasi $/ S D=\sqrt{ }\left(\frac{(x i-x)^{2}}{30}\right)$
$=3,97$

$$
\begin{aligned}
\text { P } 95 \%=29,7+ & (1,65 \times 3,97) \\
= & 29,7+6,55 \\
= & \mathbf{3 6 , 2 5} \mathrm{cm} \\
& \\
\text { P } 5 \% \quad 29,7-(1,65 \times 3,97) & =29,7-6,55 \\
= & \mathbf{2 3 , 1 5} \mathrm{cm}
\end{aligned}
$$

Tinggi pantat-bahu/tinggi sandaran bahu menggunakan persentil $95^{\text {th }}$ yaitu $53,96 \mathrm{~cm}=\mathbf{5 4} \mathrm{cm}$. penggunaan persentil tersebut dimaksudkan agar wanita hamil yang memiliki postur punggung pendek dapat menggunakan sandaran tersebut, juga wanita hamil yang memiliki postur punggung tinggi tetap bisa menggunakan sandararan dan menopang punggung secara keseluruhan. wanita hamil yang memiliki postur tinggi tetap bisa menggunakan sandararan dan menopang punggung serta kepala secara keseluruhan.

Jarak lumbar-pusar/space untuk perut bilamana ada fitur meja menggunakan persentil 50th yaitu $29,7 \mathrm{~cm}$. penggunaan persentil tersebut dimaksudkan untuk rata-rata seluruh populasi karena ukuran keadaaan perut yang tidak mudah ditentukan. Adanya penambahan allowance sebesar $26 \mathrm{~cm}$, menjadi $29,7+26=\mathbf{5 6} \mathrm{cm}$. penambahan tersebut didapat dari panambahan lingkar perut $1 \mathrm{~cm}$ perminggunya dari kehamilan 12 minggu - 38 minggu [15]. dimaksudakan untuk fitur meja yang adjustable dengan perpanjangan maksimal sampai 56 $\mathrm{cm}$ karena perkembangan janin yang terus membesar, agar ketika fitur meja digunakan, perut yang membesar tidak terbentur atau terhalang. 


\section{Lebar Pinggul}

Standar Deviasi $/ S D=\sqrt{ }\left(\frac{(x i-x)^{2}}{30}\right)$
$=5,94$

$P 95 \%=49,4+(1,65 \times 5,94)$

$=49,4+9,8$

$=59,2 \mathrm{~cm}$

P 5\% = 49,4 - $(1,65 \times 5,94)$

$=49,4-9,8$

$=39,6 \mathrm{~cm}$

\section{Tinggi Pantat}

Standar Deviasi $/ S D=\sqrt{ }\left(\frac{(x i-x)^{2}}{30}\right)$
$=3,17$

P 95\% $=19,2+(1,65 \times 3,17)$

$=19,2+5,23$

$=24,43 \mathrm{~cm}$

$P 5 \%=19,2-(1,65 \times 3,17)$

$=19,2-5,23$

$=13,97 \mathrm{~cm}$

\section{Lebar Bahu}

Standar Deviasi $/ S D=\sqrt{ }\left(\frac{(x i-x)^{2}}{30}\right)$
$=4,13$

$$
\begin{array}{rl}
\text { P 95\% = 46,7+ }(1,65 \times 4,13) \\
= & 46,7+6,81 \\
= & 53,51 \mathrm{~cm} \\
& \\
\text { P } 5 \% \quad 4 & 46,7-(1,65 \times 4,13) \\
= & 46,7-6,81 \\
= & 39,89 \mathrm{~cm}
\end{array}
$$

Lebar pinggul/lebar alas duduk menggunakan persentil $95^{\text {th }}$ yaitu $59,2 \mathrm{~cm}=60 \mathrm{~cm}$. penggunaan persentil tersebut dimaksudkan agar wanita hamil yang memiliki lebar pinggul besar dan kecil dapat menggunakanya dengan nyaman, lebih leluasa. Jika dibandingkan dengan ukuran nasioanal wanita indonesia sangat berbeda yaitu persentil $95^{\text {th }}$ sebesar $45 \mathrm{~cm}$ [16]. ukuran tersebut dikarenakan pinggul wanita hamil mengalami pembesaran dan melebar, sehingga pengukuran tersebut sangat tepat untuk dilakukan dan dapat diketahui perbandinganya dengan orientasi ukuran wanita tubuh normal.

Tinggi pantat menggunakan persentil $95^{\text {th }}$ yaitu $24,43 \mathrm{~cm}=\mathbf{2 5}$ cm. penggunaan persentil tersebut dimaksudkan agar wanita hamil yang memiliki tinggi pantat yangg rendah dan juga tinggi dapat menggunakan ukuran in.

Lebar bahu/ lebar sandaran menggunakan persentil $95^{\text {th }}$ yaitu $53,51 \mathrm{~cm}=54 \mathbf{c m}$. penggunaan persentil tersebut dimaksudkan agar wanita hamil yang memiliki lebar bahu kecil dan besar dapat tetap ditopang seacara keseluruhan serta lebih leluasa. 


\section{Kesimpulan}

Berdasarkan hasil penelitian dan pembahasan pada bab sebelumnya, maka dapat ditarik kesimpulan sebagai berikut :

1. Ukuran data antropometri wanita hamil yang telah didapat:

- Tinggi Popliteal dengan rata-rata $38,2 \mathrm{~cm}$, persentil $5^{\text {th }}$ adalah $32,23 \mathrm{~cm}$, dan persentil $95^{\text {th }}$ adalah $44,17 \mathrm{~cm}$.

- Panjang Popliteal dengan rata-rata $44,7 \mathrm{~cm}$, persentil $5^{\text {th }}$ adalah $37,1 \mathrm{~cm}$, dan persentil $95^{\text {th }}$ adalah $52,3 \mathrm{~cm}$.

- $\quad$ Tinggi pantat-siku dengan rata-rata $23,7 \mathrm{~cm}$, persentil $5^{\text {th }}$ adalah $18,31 \mathrm{~cm}$, dan persentil $95^{\text {th }}$ adalah $29,09 \mathrm{~cm}$.

- Jarak ujung jari-siku dengan rata-rata $38,4 \mathrm{~cm}$, persentil $5^{\text {th }}$ adalah $34,16 \mathrm{~cm}$, dan persentil $95^{\text {th }}$ adalah $42,64 \mathrm{~cm}$.

- $\quad$ Tinggu Lumbar dengan rata-rata $27,1 \mathrm{~cm}$, persentil $5^{\text {th }}$ adalah $20,21 \mathrm{~cm}$, dan persentil $95^{\text {th }}$ adalah $33,99 \mathrm{~cm}$.

- Tinggi pantat-bahu dengan rata-rata $50,2 \mathrm{~cm}$, persentil $5^{\text {th }}$ adalah $43,31 \mathrm{~cm}$, dan persentil $95^{\text {th }}$ adalah 53,96 cm.

- Tinggi duduk normal dengan rata-rata $73,8 \mathrm{~cm}$, persentil $5^{\text {th }}$ adalah $64,51 \mathrm{~cm}$, dan persentil $95^{\text {th }}$ adalah $83,08 \mathrm{~cm}$.

- Jarak lumbar-pusar dengan rata-rata $29,7 \mathrm{~cm}$, persentil $5^{\text {th }}$ adalah $23,15 \mathrm{~cm}$, dan persentil $95^{\text {th }}$ adalah $36,25 \mathrm{~cm}$.

- Lebar pinggul dengan rata-rata $49,4 \mathrm{~cm}$, persentil $5^{\text {th }}$ adalah $39,6 \mathrm{~cm}$, dan persentil $95^{\text {th }}$ adalah 59,2 $\mathrm{cm}$.

- $\quad$ Tinggi Pantat dengan rata-rata $19,2 \mathrm{~cm}$, persentil $5^{\text {th }}$ adalah $13,97 \mathrm{~cm}$, dan persentil $95^{\text {th }}$ adalah $24,43 \mathrm{~cm}$.

- Lebar bahu dengan rata-rata $46,7 \mathrm{~cm}$, persentil $5^{\text {th }}$ adalah $38,89 \mathrm{~cm}$, dan persentil $95^{\text {th }}$ adalah 53,51 $\mathrm{cm}$.

2. Dimensi yang akan diaplikasikan pada Desain Kursi Kerja Penunjang Kegiatan Work From Home Bagi Karyawati Hamil :

- Ukuran tinggi kaki kursi/tinggi alas duduk menggunakan persentil $5^{\text {th }}$ yaitu $32,23 \mathrm{~cm}=33 \mathrm{~cm}$.

- Ukuran panjang alas duduk menggunakan persentil $50^{\text {th }}$ yaitu $44,7 \mathrm{~cm}=45 \mathrm{~cm}$.

- Ukuran tinggi sanggahan tangan/tinggi arm rest menggunakan persentil $5^{\text {th }}$ yaitu $18,31 \mathrm{~cm}=1 \mathbf{1 8 , 5}$ cm.

- Ukuran panjang sanggahan tangan/panjang arm rest menggunakan persentil $50^{\text {th }}$ yaitu $38,4 \mathrm{~cm}=$ $38,5 \mathrm{~cm}$

- Ukuran tinggi bantalan lumbar/tinggi lumbar support menggunakan persentil $5^{\text {th }}$ yaitu $20,21 \mathrm{~cm}=$ $20,5 \mathrm{~cm}$.

- Ukuran tinggi sandaran bahu menggunakan persentil $95^{\text {th }}$ yaitu $53,96 \mathrm{~cm}=\mathbf{5 4} \mathbf{c m}$

- Ukuran tinggi sandaran sampai kepala menggunakan persentil $95^{\text {th }}$ yaitu $83,08 \mathrm{~cm}=83 \mathrm{~cm}$.

- Ukuran space untuk perut bilamana ada fitur meja menggunakan persentil $50^{\text {th }}$ yaitu $29,7 \mathrm{~cm}+26$ $\mathrm{cm}=56 \mathrm{~cm}$.

- Ukuran lebar alas duduk menggunakan persentil $95^{\text {th }}$ yaitu $59,2 \mathrm{~cm}=\mathbf{6 0} \mathrm{cm}$

- Ukuran tinggi pantat menggunakan persentil $95^{\text {th }}$ yaitu $24,43 \mathrm{~cm}=25 \mathrm{~cm}$

- Ukuran lebar sandaran menggunakan persentil $95^{\text {th }}$ yaitu $53,51 \mathrm{~cm}=\mathbf{5 4} \mathbf{c m}$. 


\section{Referensi}

[1] A. Kusumawati, "400.000 lebih angka kehamilan meningkat saat Pandemi Corona," The Asian Parent Indonesia, 20 mei 2020.

[2] B. P. Statistik, Profil Perempuan Indonesia, Jakarta: Kementrian Pemberdayaan Perempuan dan Perlindungan Anak, 2018.

[3] KEMENPAG, "Terapkan WFH Bagi Karyawan Hamil, Menteri Bintang Apresiasi Komitmen Mendagri," Kementrian Pemberdayaan Perempuan dan Perlindungan Anak Republik Indonesia, 18 maret 2020.

[4] D. P. A. Emi Nurlaela, "Gambaran Kesehatan Ibu Hamil Berdasarkan Aktivitas Kerja Di Puskesmas Buaran," Jurnal IImiah Kesehatan (JIK) Vol XI, No II, September 2018 ISSN 1978-3167, E-ISSN 2580-135X. STIKES Muhammadiyah Pekajangan Pekalongan, 2018.

[5] M. B. D. R. R. C. C. M. J. E. M. B. Sinclair Marlene PhD, " How do Women Manage PregnancyRelated Low Back and/or Pelvic Pain? Descriptive Findings from An Online Survey," Newabey: The Royal College of Midwives, pp. Evidence Based Midwifery 12(3): 76-82, 2014.

[6] E. S. P. d. M. A. Waskito, "Konsep Ergonomi kultural nusantara dalam pendidikan dasar Desain Produk ITENAS," Program Studi Desain Produk, Fakultas Seni Rupa dan Desain, Institut Teknologi Nasional Bandung, Indonesia, p. 2, 8 juli 2020.

[7] A. Bidan Epi Sundari, Interviewee, Wawancara Ahli Kandungan. [Interview]. 12 Oktober 2020.

[8] L. K. Wardani, "Evaluasi Ergonomi Dalam Perancangan Desain," Staf Pengajar Fakultas Seni dan Desain, Jurusan Desain Interior Universitas Kristen Petra Surabaya, p. 71, 2003.

[9] R. Zulfhi, S. Wardah and H. Hasanah, "Penggunaan Data Antropometri dalam Evaluasi Ergonomi Pada TempatDuduk Penumpang Speed Boat Rute Tembilahan - Kuala Enok Kab.Indragiri Hilir Riau," p. 1, 2013.

[10] K. a. Katharine, "Evolution of mid range theory of comfort for outcomes research," Nursing Outlook, vol. 49, 2001.

[11] N. d. Eko, Ergonomi Konsep Dsar dan Aplikasinya, Surabaya: Guna Widya, 2001.

[12] A. R. Tilley and H. Dreyfuss, THE MEASURE OF MEN AND WOMEN, New York: Whitney Library Of Design, 1993.

[13] Z. a. M. Z. Panero, Dimensi Manusia \& Ruang Interior, Jakarta: Erlangga, 2003.

[14] P. a. Stephent, Bodyspace : Anthropometry, Ergonomic and The Design of Work, London: Taylor and Francis inc, 2003.

[15] d. A. B. I. Noya, "Penyebab Ukuran Perut Ibu Hamil Tampak Besar atau Kecil," Alodokter.com, 10 April 2019. [Online]. Available: https://www.alodokter.com/penyebab-ukuran-perut-ibuhamil-tampak-besar-atau-kecil. [Accessed 7 Desember 2020]. 